\title{
ESTUDO COMPARATIVO DO TONO MUSCULAR NA PARALISIA CEREBRAL TETRAPARÉTICA EM CRIANÇAS COM LESÕES PREDOMINANTEMENTE CORTICAIS OU SUBCORTICAIS NA TOMOGRAFIA COMPUTADORIZADA DE CRÂNIO
}

\author{
Cristina Iwabe', Ana Maria Sedrez Gonzaga Piovesana²
}

\begin{abstract}
RESUMO - Objetivo: Comparar a distribuição e intensidade do tono muscular na paralisia cerebral tetraparética espástica (PC-T), correlacionando os dados clínicos com a localização da lesão no sistema nervoso central. Método: Foram incluídas 12 crianças de dois a quatro anos de idade com lesões predominantemente corticais (seis crianças) e subcorticais (seis crianças). 0 tono foi analisado nos membros superiores (MMSS) e inferiores (MMII) baseado no protocolo de Durigon e Piemonte. Resultados: Não houve diferença significante quanto à intensidade e distribuição de tono em MMSS e MMII nos dois grupos. Comparando os MMSS e MMII de sujeitos do mesmo grupo, os MMII apresentaram mais assimetrias e maior intensidade do tono do que os MMSS. Conclusão: Neste estudo, crianças com PC devido a lesões predominantemente corticais ou subcorticais apresentam déficit semelhante na modulação de tono, ocasionando distribuição simétrica e homogênea de hipertonia que predomina em MMII.
\end{abstract}

PALAVRAS-CHAVE: paralisia cerebral, tono muscular, sistema nervoso central.

\begin{abstract}
Comparative study of muscular tonus in spastic tetraparetic cerebral palsy in children with predominantly cortical and subcortical lesions in computerized tomography of the skull

ABSTRACT - Objective: To compare distribution and intensity of muscular tonus in spastic tetraparetic cerebral palsy (CP), correlating the clinical data with lesion location in the central nervous system. Method: Twelve children aged two to four years old with predominantly cortical lesions (six children) and subcortical lesions (six children) were included. The tonus was analyzed in the upper (UULL) and lower limbs (LLLL) based on Durigon and Piemonte protocol. Result: There was no significant difference regarding tonus intensity and distribution in the UULL and LLLL in both groups. Comparing the upper and lower limbs of subjects in the same group, the LLLL presented more asymmetry and higher tonus intensity than the UULL. Conclusion: In this study children with CP as a result of predominantly cortical or subcortical lesions present a similar deficit in tonus modulation, causing a symmetric and homogeneous distribution of hypertonicity, which is predominant in the LLLL.
\end{abstract}

KEY WORDS: cerebral palsy, muscular tonus, central nervous system.

Brouwer e Ashby ${ }^{1}$ designam paralisia cerebral (PC) como um grupo de distúrbios cerebrais de caráter estacionário, devido a lesão ou anomalia do desenvolvimento cerebral, ocorridas durante a vida fetal ou durante os primeiros meses de vida. Tais distúrbios caracterizam-se pela falta de controle sobre os movimentos, pelas modificações adaptativas do comprimento do músculo e também pelas deformidades ósseas. O tono muscular é caracterizado pelo grau de resistência ao alongamento passivo, apre- sentando componentes distintos, como a inércia da extremidade, as propriedades mecânicas elásticas dos tecidos musculares e conjuntivas e o reflexo de contração muscular ${ }^{2}$, sendo modulado apropriadamente para a manutenção da postura e dos movimentos voluntários ${ }^{3}$. O circuito neural básico para a modulação do tono muscular é o arco reflexo, consistindo dos receptores musculares, conexão central com os neurônios medulares e motoneurônios. Este circuito é influenciado por fatores modulatórios que

Departamento de Neurologia e Serviço de Fisioterapia Neurologia Infantil do Hospital das Clínicas da Faculdade de Ciências Médicas (FCM) da Universidade Estadual de Campinas, (UNICAMP) Campinas SP Brasil: ${ }^{1}$ Fisioterapeuta, mestranda em neurociência, UNICAMP: 2Professora Doutora UNICAMP, Responsável pelo Ambulatório Multidisciplinar de Paralisia Cerebral e Neurologia Infantil.

Recebido 11 Outubro 2002, recebido na forma final 26 Fevereiro 2003. Aceito 18 Março 2003.

Fta. Cristina Iwabe - Rua Pereira Barreto 413, Chácara da Barra - 13092-780 Campinas SP - Brasil. 
associados aos tratos neurais originados de estruturas supra-segmentares e formações situadas no tronco encefálico exercem a modulação do comportamento do tono muscular². O trato córtico-espinhal e o retículo-espinhal bulbar exercem influência inibitória sobre os motoneurônios destinados aos músculos anti-gravitários; os tratos vestíbulo-espinhal e retículo-espinhal pontino exercem intensa ação facilitatória sobre os motoneurônios destinados aos músculos anti-gravitários ${ }^{3,4}$. O equilíbrio das influências facilitatórias e inibitórias permite a modulação adequada e controle do tono muscular. Lesões no sistema nervoso central (SNC) interferem neste equilíbrio do controle do tono muscular. Na PC espástica, os circuitos neurais que modulam o tono estão cronicamente comprometidos, levando a mudanças nas propriedades elétricas intrínsecas dos neurônios. Isto se deve a alteração na condutância da membrana, mediada por aumento da concentração de moduladores neurais, como a serotonina, que provocariam um pulso despolarizante prolongado.
Outra hipótese para explicar a alteração progressiva do tono muscular seria as alterações estruturais permanentes nas propriedades mecânicas intrínsecas dos tecidos musculares ${ }^{2}$.

Estudos recentes valorizam a importância da neuroimagem associada à avaliação clinica e ao prognóstico da $\mathrm{PC}^{5-7}$. Porém, não encontramos pesquisas relacionando as lesões cerebrais e o tono muscular. Nosso objetivo é aprofundar o conhecimento sobre a avaliação do tono muscular na PC tetraparética (PC-T), correlacionando com a lesão cerebral.

\section{MÉTODO}

Foram incluídas 12 crianças na faixa etária de dois a quatro anos de idade, com diagnóstico de PC-T devida a etiologia perinatal, selecionadas no Ambulatório de Fisioterapia Aplicada à Neurologia Infantil da UNICAMP a partir de exames de tomografia computadorizada (TC). Constituíram-se dois grupos: G1- lesões de predomínio cortical (seis crianças) e G2 - lesões de predomínio subcortical (seis crianças). Foram excluídas crianças com malformações ou

Tabela 1. Dados de identificação.

\begin{tabular}{|c|c|c|c|c|c|c|}
\hline & Gênero & $\begin{array}{c}\text { Data de } \\
\text { nascimento }\end{array}$ & Peso(g) & $\begin{array}{c}\text { IG } \\
\text { (semanas) }\end{array}$ & Fatores de risco & $\mathrm{TC}$ \\
\hline \multicolumn{7}{|l|}{ Suj G1 } \\
\hline 1 & $\mathrm{~F}$ & $01 / 06 / 95$ & 2800 & 37 & Asfixia +EHI & $\begin{array}{l}\text { Área hipoatenuante reg frontal + } \\
\text { NB + tálamo }\end{array}$ \\
\hline 2 & M & 26/09/96 & 3075 & 37 & $\mathrm{PCR}$ perinatal $+\mathrm{EHI}$ & Lesões hipodensas corticais bilateral \\
\hline 3 & $\mathrm{~F}$ & $26 / 08 / 97$ & 3000 & 40 & $\begin{array}{l}\text { Descolamento placenta+ } \\
\text { EHI+ PCR perinatal }\end{array}$ & $\begin{array}{l}\text { Área hipodensa no } \\
\text { centro semioval }\end{array}$ \\
\hline 4 & $\mathrm{M}$ & 06/10/94 & 3000 & 38 & $\begin{array}{l}\text { Asfixia }+\mathrm{EHI}+ \\
\text { distress respiratório }\end{array}$ & $\begin{array}{l}\text { Hipoatenuação difusa do } \\
\text { parênquima + redução sulco cortical }\end{array}$ \\
\hline 5 & $\mathrm{~F}$ & 03/09/97 & 1550 & 33 & $\begin{array}{l}\text { Prematuridade } \\
+\mathrm{DHEG}+\mathrm{EHI}\end{array}$ & $\begin{array}{l}\text { Hipoatenuação parieto-occipital + } \\
\text { atrofia cortico-subcortical }\end{array}$ \\
\hline 6 & $\mathrm{~F}$ & $12 / 06 / 98$ & 2905 & 38 & $\mathrm{EHI}+\mathrm{DHEG}$ & Atrofia cortical difusa \\
\hline \multicolumn{7}{|l|}{ Suj G2 } \\
\hline 7 & $\mathrm{M}$ & 28/09/96 & 3075 & 36 & $\begin{array}{l}\text { DHEG + anóxia } \\
\text { perinatal + EHI }\end{array}$ & $\begin{array}{l}\text { Leucomalácia } \\
\text { difusa subcortical }\end{array}$ \\
\hline 8 & $\mathrm{M}$ & $12 / 04 / 97$ & 1020 & 29 & $\begin{array}{l}\text { Trigemelar }+ \\
\text { anemia na gestação }\end{array}$ & $\begin{array}{l}\text { Dilatação do corno } \\
\text { temporal ventricular lateral direito }\end{array}$ \\
\hline 9 & $\mathrm{M}$ & $26 / 09 / 98$ & 1500 & 28 & $\mathrm{EHI}$ & Hemorragia periventricular \\
\hline 10 & $\mathrm{M}$ & $17 / 12 / 96$ & 820 & 24 & Prematuridade + DHEG & Hemorragia periventricular \\
\hline 11 & $\mathrm{M}$ & $11 / 07 / 98$ & 1295 & 29 & Prematuridade $+\mathrm{PCR}+\mathrm{EHI}$ & Leucomalácia subcortical \\
\hline 12 & $\mathrm{M}$ & $12 / 08 / 98$ & 1300 & 30 & $\mathrm{EHI}$ & Hemorragia periventricular \\
\hline
\end{tabular}

IG, idade gestacional; M, masculino; F, Feminino; TC, tomografia computadorizada; EHI, encefalopatia hipóxico isquêmica; PCR, parada cardio respiratória; NB, núcleos da base; DHEG, doença hipertensiva específica da gravidez. 
Tabela 2. Níveis descritivos para a comparação da assimetria em cada grupo muscular entre os grupos de lesão (G1 x G2).

\begin{tabular}{lccc}
\hline Grupo Muscular & \multicolumn{3}{c}{ Grupo de lesão } \\
& \multicolumn{4}{c}{ G1 } & Média & p-valor \\
\hline Inversores de tornozelos & 16,67 & 83,38 & 0,08 \\
Extensores de quadril & 66,67 & 0,00 & 0,06 \\
Adutores de ombro & 0,00 & 83,33 & $0,01^{*}$ \\
\hline
\end{tabular}

*diferença significante

Tabela 3. Níveis descritivos para amostras relacionadas, comparando a assimetria muscular de distribuição de tono muscular entre os MMSS e MMII para cada grupo de lesão na mesma criança.

\begin{tabular}{lcc}
\hline Grupo Muscular & \multicolumn{2}{c}{ Grupo de lesão } \\
& G1 & G2 \\
& \multicolumn{2}{c}{ Média } \\
\hline Membros superiores & 4,0 & 6,17 \\
Membros inferiores & 9,5 & 11,33 \\
p-valor & $0,03^{*}$ & $0,03^{*}$ \\
\hline
\end{tabular}

* diferença significante

Tabela 4. Níveis descritivos para amostras relacionadas, comparando a intensidade muscular de tono muscular entre os MMSS e MMII para cada grupo de lesão na mesma criança.

\begin{tabular}{|c|c|c|}
\hline \multirow[t]{3}{*}{ Grupo Muscular } & \multicolumn{2}{|c|}{ Grupo de lesão } \\
\hline & G1 & $\mathrm{G} 2$ \\
\hline & \multicolumn{2}{|c|}{ Média } \\
\hline Membros superiores & 80,67 & 82,17 \\
\hline Membros inferiores & 99,17 & 98,33 \\
\hline$p$-valor & $0,03^{*}$ & 0,06 * \\
\hline
\end{tabular}

*diferença significante

infecções do SNC, síndromes genéticas, uso de toxina botulínica há menos de seis meses, deformidades estruturadas, deficiência mental grave (Tabela 1).

O protocolo de avaliação utilizado foi o proposto por Durigon e Piemonte ${ }^{8}$, fundamentado em princípios neurofisiológicos associados à observação clínica, considerando três aspectos: capacidade de adaptação do fuso muscular ao movimento, intensidade da reação ao alongamento e variação da hipertonia em relação à velocidade do movimento.

As crianças foram avaliadas em decúbito dorsal com cabeça e tronco alinhados, realizando a mobilização passiva de todas as articulações individualmente, em todos os arcos de movimento, registrando a reação ao alongamento dos vários grupos musculares.

Os resultados foram analisados pela Comissão de Pesquisa - Estatística da FCM/UNICAMP e foram utilizados o teste exato de Fisher para comparação de proporções, o teste Mann-Whitney para comparação de variáveis contínuas ou ordenáveis entre os grupos e o teste de Wilcoxon para comparação das variáveis entre os dimídios de cada grupo. O nível de significância adotado foi $5 \%(p<0,05)$.

Este estudo foi aprovado pelo Comitê de Ética em Pesquisa da FCM/UNICAMP. Todos os responsáveis pelas crianças assinaram termo de consentimento livre e esclarecido.

\section{RESULTADOS}

$\mathrm{Na}$ análise da assimetria de cada grupo muscular nos membros inferiores (MMII), comparando G1 e G2, observou-se no G1 tendência a apresentar maior assimetria de tono muscular em relação aos extensores de quadril e no $\mathrm{G} 2$ nos inversores de tornozelo. Não houve diferença significante quanto à comparação da assimetria do tono muscular de MMII, quando foi realizada a somatória da distribuição de intensidade do tono de cada grupo (G1 e G2) $(p>0,05)$. Nos membros superiores (MMSS) constatou-se maior assimetria nos adutores de ombro $(p=0,01)$ no $G 2$ (Tabela 2$)$.

Na pesquisa da assimetria do tono muscular associando os MMSS e MMII, não houve diferença significante, considerando a somatória da distribuição de intensidade do tono de cada grupo (G1 e G2) $(p>0,05)$.

Analisando a intensidade do tono muscular nos dimídios direito e esquerdo, tanto nos MMII quanto nos MMSS, não houve diferença significante intragrupo e intergrupos (G1 e G2) ( $p>0,05)$.

Em relação à comparação da assimetria de distribuição da intensidade de tono muscular entre os MMSS e MMII, em cada grupo de lesão na mesma criança, observaram-se diferenças significantes tanto no $G 1$ quanto no $G 2(p<0,05)$. Nos dois grupos, os MMII apresentaram maiores assimetrias (Tabela 3).

Em relação à comparação da intensidade de tono muscular entre os MMSS e MMII, em cada grupo de lesão na mesma criança, observaram-se diferenças significantes no $\mathrm{G} 1(p<0,05)$ apresentando os MMII maiores intensidades. No G2, os MMII apresentaram apenas tendência a esta correlação (Tabela 4).

\section{DISCUSSÃO}

Dentre as principais etiologias da PC, as lesões cerebrais hipóxico-isquêmicas são as mais observadas. As diferentes formas clínicas apresentadas dependem da intensidade dos fenômenos isquêmicos e da época da ocorrência ${ }^{9-11}$. Quando a criança encontra-se em estado de déficit de oxigenação, desencadeia-se uma série de processos automáticos e defensivos, a fim de reagir contra a agressão hipóxico- 
isquêmica. Inicialmente, ocorre aumento da perfusão sangüínea cerebral, seguido por diminuição do fluxo sangüíneo local, edema cerebral, diminuição do fluxo sangüíneo generalizado e necrose ${ }^{9-12}$. Portanto, as lesões hipóxico-isquêmicas apresentam um local principal de lesão, com imagens seqüelares, geralmente hipodensas. As áreas cerebrais adjacentes podem sofrer lesão metabólica acarretando disfunção, sem haver necessariamente perda tecidual.

No início deste estudo, partiu-se da hipótese de que lesões cerebrais ocasionassem comprometimento assimétrico do tono muscular, baseada no enunciado de Volpe ${ }^{10}$ : "As lesões vasculares corticais próprias do recém nascido a termo tendem a apresentarem-se assimétricas, assim como as lesões subcorticais do prematuro, principalmente na porencefalia póshemorrágica subcortical". Nesta casuística, predominou simetria na maioria dos grupos musculares estudados, tanto entre MMII e MMSS quanto nos dimídios esquerdo e direito, concordando com Greisen ${ }^{12}$ que afirma serem as lesões cerebrais hipóxico-isquêmicas sistematicamente bilaterais e simétricas.

Consideramos que, apesar de algumas lesões cerebrais apresentadas pelos sujeitos com PC-T serem relativamente extensas, as lesões de predomínio subcortical dos nossos sujeitos interferiram principalmente com a trajetória do feixe piramidal destinado aos $\mathrm{MMII}^{10}$, resultando no maior comprometimento crural embora de intensidade assimétrica. Outra explicação consideraria que no grupo $\mathrm{G} 1$, as colunas corticais mais envolvidas seriam as responsáveis pelos movimentos dos MMII baseando-se no princípio de que o córtex cerebral possui organização colunar, no qual cada coluna controla um mesmo músculo, relacionado a determinado movimento funcional ${ }^{13}$.

Estudos com neuroimagem funcional têm proporcionado avanços no entendimento das correlações entre o momento e o local das lesões cerebrais com a evolução clínica ${ }^{14-16}$. Porém, não foram evidenciadas correlações com o comprometimento específico do tono muscular, embora Yim et al. ${ }^{17}$ referissem na PC-T a correlação entre o grau do comprometimento motor e a hipoperfusão do tálamo.

\section{CONCLUSÃO}

Tanto as lesões corticais quanto as subcorticais ocasionam quadros motores característicos, dependendo, entre outros, do local e da extensão da lesão. Dentre as disfunções observadas, a alteração de tono muscular é um dos sinais mais freqüentes nas crianças com PC. Comparando assim os dois grupos de estudos especificados, as crianças apresen- taram deficiências semelhantes na modulação do tono muscular, distribuído nos dois dimídios de modo simétrico e homogêneo, embora com maior intensidade nos MMII. Estas lesões alteram tanto a qualidade como a quantidade dos movimentos a serem executados, exigindo estratégias compensatórias para aumentar a estabilidade articular, limitar os graus de liberdade, ou permitir que o sistema motor responda mais prontamente a perturbações do meio. Por outro lado, deve-se considerar que esta casuística foi composta por sujeitos com boa "performance" cognitiva, que por si só impõe um trabalho de autoreabilitação e maior funcionalidade dos MMSS, o que pode interferir na evolução do tono muscular e da função motora. Pelo fato de nossas hipóteses não estarem confirmadas, torna-se necessária a continuidade deste estudo com a ampliação do número de sujeitos, associação com a performance da função motora e neuroimagem funcional. Acreditamos que aprofundar o conhecimento destes aspectos poderá trazer novos esclarecimentos, a fim de otimizar a intervenção terapêutica.

\section{REFERÊNCIAS}

1. Brouwer B, Ashby P. Altered corticospinal projections to lower limb motoneurons in subjects with cerebral palsy. Brain 1991;114:1398-1407.

2. Katz RT, Rymer Z. Spastic hypertonia: mechanisms and measurement. Arc Phys Med Rehabil 1989;70:144-155.

3. Kandel ER, Schwartz JH, Jessel TM. Essential of neural science and behavior. New York: Appleton \& Lange, 1995:489-549.

4. Shumway-Cook A, Woollacott MH. Motor control: theory and practical apllications. 2. Ed. Philadelphia: Lippincott William \& Wilkins, 2000:127-139.

5. Gururaj A, Sztriha L, Dawodu A, et al. CT and MR patterns of hypoxic ischemic brain damage following perinatal asphyxia. J Trop Pediatric 2002;48:5-9.

6. Piovesana AMSG, Moura-Ribeiro MVL, Zanardi VA, Gonçalves VMG Hemiparetic cerebral palsy: risk factors for etiology and neuroimaging. Arq Neuropsiquiatr 2001;59:29-34.

7. Blankenberg FG, Loh NN, Bracci P, et al. Sonography, CT and MR imaging: a prospective comparasion of neonates with suspected intracranial ischemia and hemorrhage. AJNR 2000;21:213-218.

8. Durigon OFS, Piemonte MEP. Desenvolvimento de protocolo para avaliação do tono muscular. Abstr.XI Congresso Brasileiro de Fisioterapia e IV Congresso Paulista de Fisioterapia. São Paulo, 1993:31.

9. Diament, A. Encefalopatia crônica da infância (paralisia cerebral). In Diament A, Cypel S. (EDS) Neurologia infantil. 3. Ed. São Paulo: Atheneu, 1996:781-798.

10. Volpe JJ. Neurology of the newborn. 3. Ed. Philadelphia: Saunders, 2000:363.

11. Piovesana AMSG. Encefalopatias infantis não progressivas - paralisia cerebral - etiologia, classificação e tratamento. In Fonseca L F, Xavier C C (eds). Compêndio de neurologia infantil. Belo Horizonte: Medsi, 2002:825-838.

12. Greisen G. Ischaemia of the preterm brain. Biol Neon 1992;62:243-247.

13. Lent R. Cem bilhões de neurônios: conceitos fundamentais de neurociências. São Paulo: Atheneu, 2001:375-400.

14. Christophe C, Fonteyne C, Ziereisen F, et al. Value of MR imaging of the brain in children with hypoxic coma. AJNR 2002;23:716-723.

15. Sie LT, Van der Knaap MS, Oosting J, de Vries LS, Lafeber HN, Valk J. MR patterns of hypoxic-ischemic brain damage after prenatal, perinatal or postnatal asphyxia. Neuropediatrics 2000;31:128-136.

16. Shah S, Fernandez AR, Chirla D. Role of brain SPECT in neonates with hypoxic ischemic encephalopathy and its correlation with neurodevelopmental outcome. Ind Pediat 2001;38:705-713.

17. Yim SY, Lee IY, Park CH, Kim OH. A qualitative analysis of brain spect for prognostication of gross motor development in children with cerebral palsy. Clin Nucl Med 2000;25:268-272. 